\title{
Equações no comportamento de trigos no sistema com resíduo de milho em condição de fracionamento de nitrogênio
}

\author{
Ana Paula Brezolin* Juliane S. P. Costa Rubia D. Mantai Marcos V. Romitti \\ Marnei D. Zorzella José Antônio G. da Silva \\ Departamento de Ciências Exatas e Engenharias, DCEEng, UNIJUÍ \\ 98700-000, Ijuí, RS \\ E-mail: anabrezolin@ hotmail.com
}

\begin{abstract}
RESUMO
O trigo, Triticum aestivum L., é um cereal básico para a civilização como uma fonte fundamental de nutrientes e energia dentro da cadeia alimentícia, fornecendo cerca de $20 \%$ das calorias provenientes de alimentos consumidos pelo homem, sendo que possui uma proteína glúten - não encontrada em outros grãos [1]. Seu cultivo segue paralelo à história da antiguidade e da modernidade. É utilizado principalmente como base de farinhas para fabricar um alimento essencial para a subsistência da humanidade, o pão, e ainda é utilizado em fabricação de ração na forma de farelo de trigo para alimentação de animais.

Os sistemas de produção de trigo, no Sul do Brasil, exigem um alto grau de tecnificação para oferecer produtividade e qualidade que permitam um bom resultado econômico ao produtor e que possibilitam competir vantajosamente em um mercado cada vez mais globalizado e controlado por países com grande tradição e eficiência na produção dos grãos e produtos industrializados desses cereais [3].

A aplicação de nitrogênio no momento adequado pode aumentar a eficiência de uso do nitrogênio pelo trigo, incrementando o número de grãos por espiga e o número de espigas por área. Além dos aspectos agronômicos, a fertilização em época apropriada pode reduzir os riscos de poluição das águas subterrâneas ocasionados pelo acúmulo de nitrato [2]. Em muitos sistemas de produção, a disponibilidade de nitrogênio é quase sempre um fator limitante, influenciando o crescimento da planta mais do que qualquer outro nutriente. Dada a sua importância, o manejo do nitrogênio tem sido intensamente estudado, no sentido de maximizar a eficiência do seu uso. Para tanto, tem-se procurado diminuir as perdas do nitrogênio no solo, bem como melhorar a sua eficiência na absorção e metabolização no interior da planta.

$\mathrm{O}$ presente trabalho tem por objetivo a modelagem matemática do comportamento de trigos classe industrial pão (BRS Guamirim) e melhorador (Fundacep Nova Era) sobre o efeito de doses de nitrogênio $(\mathrm{N})$ em condições com diferentes níveis de fracionamento de $\mathrm{N}$ na variável rendimento de grãos, envolvendo sistema de cultivo com lenta liberação de $\mathrm{N}$ residual. Portanto, estudos que buscam inferências sobre as condições de produção de trigo na região noroeste do estado do Rio Grande do Sul.

O delineamento experimental foi o de blocos casualizados com quatro repetições, seguindo um modelo fatorial 2x3 sendo duas cultivares de trigo (BRS Guamirim e Fundacep e Nova Era), e três épocas de aplicação de $\mathrm{N}\left(\mathrm{V}_{3}, \mathrm{~V}_{6}\right.$ e $\left.\mathrm{R}_{1}\right)$. Em cada condição para o desenvolvimento do modelo foi empregada três doses de nitrogênio $\left(30,60,120 \mathrm{~kg} \mathrm{ha}^{-1}\right)$ para elaboração de equações de regressão em cada condição de fracionamento. Ressalta-se que para a simulação da produtividade de grãos nestas equações, foi considerada a dose de $90 \mathrm{~kg} \mathrm{ha}^{-1} \mathrm{de} \mathrm{N}$, a partir de valor que representa a realidade de uso local. As parcelas foram constituídas por cinco linhas espaçadas $0,20 \mathrm{~m}$ entre si e cinco metros de comprimento, resultando em cinco metros quadrados por parcela. A variável mensurada foi o rendimento de grãos (RG).

Na tabela 1 estão apresentadas as equações de regressão de grau 1 e 2 buscando o ajuste que permita a interpretação biológica da dose e o particionamento de N. A linearidade foi obtida apenas quando empregada uma única aplicação em $V_{3}$, ao tempo que nos momentos $V_{3} / V_{6} e$ $V_{3} / R_{1}$ a equação de segundo grau foi confirmada indicando uma tendência a estabilização. No ano favorável pelas condições climáticas a estabilidade foi obtida no estádio $\mathrm{V}_{3}$ a partir da

* Estudante de Pós-Graduação do Curso de Modelagem Matemática da UNIJUÍ e bolsista FAPERGS.
\end{abstract}


equação de grau dois e de tendência linear quando empregado o particionamento. Portanto, nestas condições a estimativa de rendimento de grãos com a inclusão de $90 \mathrm{~kg} \mathrm{~N} \mathrm{ha}^{-1}$ nas equações propostas indicaram tendência a incrementar a produção principalmente no estádio $\mathrm{V}_{3} / \mathrm{R}_{1}$. Ressalta-se que a máxima exploração do potencial genético de uma cultivar está relacionada ao melhor aproveitamento dos estímulos ambientais pela planta, sugerindo que o ajuste da dose e condição de adubação se traduzem numa eficiente alternativa em promover a produtividade.

Tabela 1. Resumo da análise de variância de equação de regressão e seus parâmetros para época e fracionamento de $\mathrm{N}$ ideal em trigo com os valores estimados de rendimento de grãos (RGE). UNIJUI, 2014.

\begin{tabular}{|c|c|c|c|c|c|c|}
\hline Condição & $\begin{array}{l}\text { Fonte de } \\
\text { Variação }\end{array}$ & $\begin{array}{l}\text { Quadrado } \\
\text { Médio(RG) }\end{array}$ & $\begin{array}{c}\text { Equação } \\
\mathrm{RG}=\mathrm{b}_{0}+\mathrm{b}_{1} \mathrm{x}+\mathrm{b}_{2} \mathrm{x}^{2}\end{array}$ & $\mathrm{P}\left(\mathrm{b}_{\mathrm{i}}\right)$ & $\begin{array}{l}\mathrm{R}^{2} \\
\%\end{array}$ & $\begin{array}{l}\operatorname{RGE}\left(\mathrm{kg} \mathrm{ha}^{-1}\right) \\
90 \mathrm{~kg} \mathrm{~N} \mathrm{ha} \\
\end{array}$ \\
\hline \multirow{3}{*}{$\mathrm{V}_{3}$} & $\mathrm{~L}$ & $7286654^{*}$ & $1109+15,2 x$ & $*$ & 91 & \multirow{3}{*}{2477} \\
\hline & Q & $623890^{*}$ & $886+30,59 x-0,12 x^{2}$ & ns & - & \\
\hline & Erro & 12739 & - & - & - & \\
\hline \multirow{3}{*}{$\mathrm{V}_{3} / \mathrm{V}_{6}$} & $\mathrm{~L}$ & $6579446^{*}$ & $1243+14,4 x$ & * & 87 & \multirow{3}{*}{2539} \\
\hline & $\mathrm{Q}$ & $915454^{*}$ & $973+33,08 x-0,14 x^{2}$ & $*$ & 99 & \\
\hline & Erro & 33547 & - & - & - & \\
\hline \multirow{3}{*}{$\mathrm{V}_{3} / \mathrm{R}_{1}$} & $\mathrm{~L}$ & $10517217^{*}$ & $1070+18,2 x$ & * & 98 & \multirow{3}{*}{2708} \\
\hline & $\mathrm{Q}$ & $100036^{*}$ & $981+24,43 x-0,049 x^{2}$ & $\mathrm{~ns}$ & - & \\
\hline & Erro & 11573 & - & - & - & \\
\hline
\end{tabular}

$\mathrm{V}_{3}=$ colar formado na $3^{\mathrm{a}}$ folha do colmo principal, $\mathrm{V}_{3} / \mathrm{V}_{6}=$ Colar formado na $6^{\mathrm{a}}$ folha do colmo principal e $V_{3} / R_{1}=$ Diferenciação da espiga; $R^{2}=$ coeficiente de determinação; $P b_{i} x=$ probabilidade da significância de inclinação; $\mathrm{L}=$ equação linear; $\mathrm{Q}=$ equação quadrática; $\mathrm{RGE}=$ Rendimento de Grãos estimado para uma expectativa de rendimento de $3 \mathrm{tha}^{-1}$.

O particionamento de nitrogênio evidencia a formação de equações que expressam comportamento médio distinto entre as cultivares de trigo testado. Contudo, o incremento das doses de nitrogênio evidencia melhor resultados no fracionamento $V_{3} / R_{1}$.

Palavras-chave: Triticum aestivum L., Regressão, Eficiência Genética

\section{Referências}

[1] B. Ana, et al. Aspectos quantitativos e qualitativos do grão de trigo influenciados por $\mathrm{N}$ e lâminas de água". Rev. bras. eng. agríc. ambient. [online], vol.15, n.5, pp. 450-457, (2011).

[2] M. R.L. et. al. Soils. Nitrogen source, timing of application, and placement: effects on winter wheat production. AgronomyJournal, Madison, v.86, p.637-642, 1994.

[3] R. Erlei Melo. Diagnose, patometria e controle de doenças de cereais de Inverno. Erlei Melo reis, Ricardo Trezzi Casa, Carlos Antônio Medeiros. Universidade de Passo Fundo, Passo Fundo, Rio Grande do Sul, 2001. 